\title{
Reinforcing the Importance of Maintaining Internship Support for College Student Engagement and Anticipated Employment
}

\author{
Gary Blau ${ }^{1}$, Corinne Snell ${ }^{1} \&$ Daniel Goldberg ${ }^{1}$ \\ ${ }^{1}$ Fox School of Business \& Management, Temple University, Philadelphia, PA, United States \\ Correspondence: Gary Blau, Human Resource Management Dept. - Fox School of Business \& Management, \\ Alter Hal \#349 (006-00) - 1801 Liacouras Walk, Temple University, Philadelphia, PA 19122, United States. \\ E-mail: gblau@temple.edu
}

Received: November 5, 2020 Accepted: December 10, 2020 Online Published: December 16, 2020

doi:10.5539/jel.v10n1p1 URL: https://doi.org/10.5539/jel.v10n1p1

\begin{abstract}
The Covid-19 pandemic has created many challenges for universities around the world, including how to keep students engaged in their professional development, despite the challenges of remote learning and virtual student services. The goal of this study was to demonstrate the continued importance of Career Professional Development Center (CPDC) support (pre-pandemic to early stages of the pandemic) for business-related internships influencing student professional development engagement (PDE) and anticipated employment upon graduation. PDE encompasses typical CPDC resources (e.g., internship search support; involvement in student professional organizations (SPOs); professional development coaching; and job search assistance). A survey, the Senior Student Satisfaction Survey (SSSS) was deployed prior to graduation to business students. Using the SSSS, two separate samples of graduating business undergraduates at a Mid-Atlantic University in the United States were surveyed, in late Spring 2019 (pre-pandemic) and late Spring 2020 (early pandemic). Pre-pandemic survey results showed that students having at least one internship experience (versus none) were more likely to: join an SPO sooner; attend more SPO meetings/semester; complete their professional development sooner; and anticipate "by graduation" full-time employment. Despite the drop in survey participation due to the pandemic onset, results consistent with this were found with the early pandemic survey. Like other academic-related and campus services in the face of the pandemic, the business school CPDC is adapting to the new remote ways of operating and successfully transitioned their delivery mode to a $100 \%$ virtual model to meet the resource challenge of supporting student PDE. It is hoped that the ideas discussed will be useful to a wider audience.
\end{abstract}

Keywords: college student engagement, expected employment, internships, pandemic

\section{Introduction}

\subsection{Introduce the Problem}

The Covid-19 pandemic continues to bring health, economic and social upheaval to millions of lives around the world. It is no different at colleges and universities, where across the globe face-to-face education has given way to remote learning (Beltemkin \& Kuyulu, 2020; Cohen \& Davidovitch, 2020; Mansoor, 2020). In the United States (US), as elsewhere, concern about college student health during the pandemic has led to increased electronic health record (EHR) integration of campus-based health services to allow better communication, monitoring, reporting and testing (Reeves et al., 2020). Not only physical health, but the mental health of college students during the pandemic has been of concern, due to such factors as forced: relocation as campuses closed, online learning, and social distancing; as well as anxiety over personal and family-related health, and economic factors, such as job loss (Liu, Pinder-Amaker, Hahm, \& Chen, 2020). Less research has been published about college student engagement and placement during the pandemic. The general purpose of this study was to reinforce the importance of mainting internship support for college student engagement and expected employment after graduation during the pandemic.

\subsection{Student Engagement}

Blau and Snell (2013) presented a model for understanding business undergraduate professional development engagement (PDE), which they defined (p. 692) as "the level of undergraduate engagement in professional development." Part of their model recognized that PDE can be operationalized using different measures, 
including: undergraduate involvement in student professional organizations (SPOs); CPDC resources utilized; and student internships.

Typically, an SPO is organized around a student's business major, e.g., accounting, business management, finance, human resources, or marketing, and such SPOs often have outside business speakers, which can lead to internship opportunities for students. Munoz, Miller and Poole (2016) found that contact with business speakers and professional development activities positively affected students' SPO participation intent. Research has found a positive relationship between students joining an SPO and obtaining internships (Blau \& Lopez, 2020).

Blau and Snell (2013) also recognized the importance of Career Professional Development Centers (CPDCs), which universities/colleges typically have as separate resources from their Counseling Services Centers (CSCs); Student Health Centers (SHCs), and Student Advising Centers (SACs). SHC services revolve around helping students with physical health-related issues; CSCs are involved with student mental health issues; and SACs assist students with curriculum and academic-related decisions. CPDC activities generally focus more on student professional development, for example, encouraging student involvement in SPOs; their personal development; career/industry awareness and impression management; resume building; interviewing; and recruiting/employer-related networking events. Thus, CPDCs play a critical role in assisting with student PDE (National Association of Colleges and Employers or NACE, 2020).

\subsection{Internships}

Students obtaining internships have been recognized as an important part of student PDE (Blau \& Snell, 2013; Blau, Blessley, Kunkle, Schirmer, \& Regan, 2017), which CPDCs strongly encourage. In their 20-year study of internships, James Cook, Stokes and Parkter (2015) found that students perceived internships led to many benefits, e.g., increased their ability to get along with others at work; facilitated one's growth in maturity; helped them to apply classroom ideas to the work environment; and increased their job search confidence. Marks, Haug and $\mathrm{Hu}$ (2018) found that internships prepared students for performance evaluations. Research has also found a positive relationship between college student internship experience and subsequent employment after graduation (Knouse \& Fontenot, 2008; Sagem, Dallam, \& Laverty, 2000). CPDCs are a critical resource for assisting students in finding internships and job opportunities (NACE, 2020).

\subsection{Research Question}

The goal of this study was to demonstrate the continued importance of CPDC support of business student internships for student PDE and anticipated employment upon graduation from pre-pandemic to early stage of the pandemic. After demonstrating this, the challenges of a CPDC continuing to support students getting internships during the pandemic are discussed as part of this CPDC's new adaptative technology and services.

\section{Method}

\subsection{Participants and Procedure}

There were two distinct samples, each sample was made up of undergraduate business students who were graduating that spring. The graduating students were surveyed in late spring 2019 (pre-pandemic) and spring 2020 (early pandemic) semesters. The business school is part of a large urban state-supported university in the Mid-Atlantic region of the United States (US). Near the end of each 14-week semester all graduating business seniors were encouraged (by their advisor and through emails) to voluntarily fill out an online Senior Student Satisfaction Survey (SSSS) prior to graduation. All the measures studied here were part of the SSSS. Data were stored in separate Qualtrics data bases. In April/May of 2019, 749 graduating seniors responded by filling out at least part of the SSSS. This represented about 70\% of the graduating seniors. In April/May 2020, 445 students filled out the SSSS, which represented approximately $37 \%$ of the graduating seniors. The sudden shift on March 13, 2020 to remote classes, and students needing to move out of campus housing due to the pandemic undoubtedly reduced the April/May 2020 participating sample size. The university institutional review board (IRB) approved the research as part of a general program review. Ninety-eight percent of each sample were full-time students (taking at least 12 credits/semester). The measures used below were the same for both surveys. It is important to note that due to the large size of the business school (over 6,000 undergraduate business students in Fall, 2019), the business school has its own CPDC, called the Center for Student Professional Development or CSPD. The activities of this CSPD focused on business student development, including: personal development, career/industry awareness and impression management, resume building, interviewing, recruiting/employer-related networking, and presenting internship and job opportunities for students.

\subsection{Measures}

Internships was measured by asking, "how many formal internships or co-ops did you complete as a student at 
this university", where none $=0,1=1,2=2,3=3,4=4,5=5$ or more.

Gender was measured as $1=$ male, $2=$ female.

Student engagement was measured using three one-item variables: when did you first join a SPO; how many SPO meetings do you attend on average during a semester; and when did you complete the CSPD professional development course or attend the required workshops? When did you first join a SPO was measured as 0 (never), $1=$ senior, $2=$ junior, $3=$ sophomore, $4=$ freshman. Average number of SPO meetings attended/semester was measured as 0 (none), $1=1-3 /$ semester, $2=4-6 /$ semester, $3=7-9 /$ semester, $4=10-12 /$ semester, and $5=13$ or more/semester. When did you complete CSPD professional development was measured as $1=$ senior year, $2=$ junior year, $3=$ sophomore year and $4=$ freshman year. There are two different ways for a student to complete this professional development. One way was to complete BA2101, a one-credit course entitled "Professional Development Strategies." The second way was to complete required CSPD virtual modules i.e., Getting Started; Resume Development; and Resume Critique.

Anticipated employment was measured using three single-item variables: will you have secured full-time (FT) employment by graduation, will you have secured FT employment by graduation in your major, and will you be self-employed by graduation? Responses for each of these items was $1=$ no, $2=$ yes. Sagem et al. (2000) used a similar dichotomous choice measurement approach. Earlier research (Blau, Williams, Jarrell, \& Nash, 2019) found a lower percentage of graduating students expected FT employment consistent with their major versus expected general FT employment. This supports keeping these two measures separate for analyses.

\subsection{Data Analyses}

Two internship group categories were created, "No Internship" versus "At Least One Intership" for each sample. Independent sample t-tests were used to compare the mean differences on variables for students in these two groups. Separate tables will be presented for the 2019 and 2020 samples. SPSS-PC (2015) was used for all data analyses.

\section{Results}

The results are shown in Table 1 (pre-pandemic 2019 sample) and Table 2 (early pandemic 2020 sample) below. Consistent results were found across both tables. There were no significant differences in gender or being self-employed by graduation for the no internship versus at least one internship groups. However, the at least one internship group joined an SPO sooner; attended a higher average number of SPO meetings/semester; completed their professional development sooner; had a higher anticipation for securing a a full-time job by graduation; and a higher anticipation for securing a full-time job in their major by graduation.

Table 1. Pre-pandemic 2019 sample independent sample t-tests comparing no internship versus at least one internship groups

\begin{tabular}{llllll}
\hline & \multicolumn{3}{l}{ No Internships $^{\mathrm{a}}$} & \multicolumn{2}{l}{ At Least One Internship $^{\mathrm{b}}$} \\
\cline { 2 - 6 } & $\mathrm{M}$ & $\mathrm{SD}$ & $\mathrm{M}$ & $\mathrm{SD}$ & $t$-test \\
\hline 1. Gender $^{\mathrm{c}}$ & 1.44 & .48 & 1.47 & .50 & -.86 \\
2. When Join SPO $^{\mathrm{d}}$ & 1.32 & 1.35 & 2.49 & 1.43 & $-9.38^{* *}$ \\
3. Average Number of SPO Meetings Attend/semester $^{\mathrm{e}}$ & 1.15 & 1.63 & 2.22 & 1.87 & $-7.25^{* *}$ \\
4. When Complete Professional Development $^{\mathrm{f}}$ & 2.40 & .77 & 2.85 & .77 & $-6.64^{* *}$ \\
5. Securing FT Job by Graduation $^{\mathrm{g}}$ & 1.50 & .50 & 1.68 & .47 & $-4.15^{* *}$ \\
6. Securing FT Job by Graduation in Major $^{\mathrm{g}}$ & 1.38 & .48 & 1.61 & .49 & $-5.20^{* *}$ \\
7. Being Self-employed by Graduation $^{\mathrm{g}}$ & 1.19 & .40 & 1.14 & .35 & 1.59 \\
\hline
\end{tabular}

Note. $* \mathrm{p}<.05, * * \mathrm{p}<.01$ (all two-tailed).

${ }^{\mathrm{a}}$ No Internships ( $\mathrm{n}=165$ to 170 , depending on missing data), ${ }^{\mathrm{b}}$ At Least One Internship ( $\mathrm{n}=579$ to 584 , depending on missing data); ${ }^{\mathrm{c}} \mathrm{Gender}$, $1=$ male, $2=$ female; ${ }^{\mathrm{d}}$ When did you first join a Student Professional Organization (SPO), $0=$ never, $1=$ senior, $2=$ junior, $3=$ sophomore, 4 $=$ freshman); ${ }^{\mathrm{e}}$ How many SPO meetings do you attend on average during a semester, $0=$ none, $1=1-3 /$ semester, $2=4-6 /$ semester, $3=$ $7-9 /$ semester, $4=10-12 /$ semester, $5=13$ or more/semester; ${ }^{\mathrm{f}}$ When did you complete the Professional Development course or attend required workshops, 1 = senior 2 = junior, 3 = sophomore, 4 = freshman; and ${ }^{\mathrm{g}}$ By graduation, will you have: secured a full-time job; secured a full-time job consistent with your major; started freelance work, consulting, or are otherwise self- employed, $1=$ no, $2=$ yes. 
Table 2. Early pandemic 2020 independent sample t-tests comparing no internship versus at least one internship groups

\begin{tabular}{|c|c|c|c|c|c|}
\hline & \multicolumn{2}{|c|}{ No Internships ${ }^{\mathrm{a}}$} & \multicolumn{3}{|c|}{ At Least One Internship ${ }^{b}$} \\
\hline & M & SD & $\mathrm{M}$ & SD & $t$-test \\
\hline 1. Gender ${ }^{\mathrm{c}}$ & 1.42 & .49 & 1.45 & .52 & -.61 \\
\hline 2. When Join $\mathrm{SPO}^{\mathrm{d}}$ & 1.30 & 1.34 & 2.62 & 1.44 & $-8.23 * *$ \\
\hline 3. Average Number of SPO Meetings Attend/semester & 1.26 & 1.78 & 2.52 & 1.94 & $-6.17 * *$ \\
\hline 4. When Complete Professional Development ${ }^{\mathrm{f}}$ & 2.39 & .77 & 3.01 & .74 & $-7.14 * *$ \\
\hline 5. Securing FT Job by Graduation ${ }^{\mathrm{g}}$ & 1.33 & .47 & 1.62 & .49 & $-5.11 * *$ \\
\hline 6. Securing FT Job by Graduation in Major ${ }^{g}$ & 1.24 & .43 & 1.55 & .50 & $-5.97 * *$ \\
\hline 7. Being Self-employed by Graduation ${ }^{g}$ & 1.16 & .37 & 1.10 & .29 & 1.48 \\
\hline
\end{tabular}

Note. $* \mathrm{p}<.05, * * \mathrm{p}<.01$ (all two-tailed)

${ }^{\mathrm{a}}$ No Internships ( $\mathrm{n}=89$ to 101 , depending on missing data), ${ }^{\mathrm{b}}$ At Least One Internship ( $\mathrm{n}=316$ to 344 , depending on missing data); ${ }^{\mathrm{c}}$ Gender, 1 $=$ male, $2=$ female $;{ }^{d}$ When did you first join a Student Professional Organization (SPO), $0=$ never, $1=$ senior, $2=$ junior, $3=$ sophomore, $4=$ freshman); ${ }^{\mathrm{e}}$ How many SPO meetings do you attend on average during a semester, $0=$ none, $1=1-3 /$ semester, $2=4-6 /$ semester, $3=$ $7-9 /$ semester, $4=10-12 /$ semester, $5=13$ or more/semester; ${ }^{\mathrm{f}}$ When did you complete the Professional Development course or attend required workshops, 1 = senior 2 = junior, 3 = sophomore, 4 = freshman; and ${ }^{\mathrm{g}}$ By graduation, will you have: secured a full-time job; secured a full-time job consistent with your major; started freelance work, consulting, or are otherwise self- employed, $1=$ no, $2=$ yes.

\section{Discussion}

After dividing students into no internship versus at least one internship groups, the results of this study demonstrated the continued importance of CPDC support for business-related internships for student PDE and anticipated employment upon graduation from pre-pandemic to early stage of the pandemic. Students with at least one internship showed higher engagement and anticipated placement. One challenge with the ongoing pandemic is to support college students who are no longer on campus to stay engaged and find internships. A college's CPDC plays a key role in helping with college student engagement, finding internships, and anticipated placement (NACE, 2020). Electronic and remote services have been put into place for academic learning (Beltemkin \& Kuyulu, 2020; Cohen \& Davidovitch, 2020; Mansoor, 2020) as well as for campus-based health services (Liu et al., 2020; Reeves et al., 2020). This has also been done for the CSPD at the business school in the present study.

When the pandemic forced US college campuses to close and students to move out in March of 2020, the CSPD was able to adapt to the new remote ways of operating and successfully transitioned their delivery mode to a $100 \%$ virtual model. This included all student services and coaching, employer services and recruitment functions, as well as a fully functioning virtual front desk. Highlights of the move to $100 \%$ virtual functioning included: moving all professional development courses (both BA 2101 and workshops/seminars) online and offered via Zoom technology. Over the Summer of 2020, additional modifications were made to the traditional in-person CSPD curriculum to increase student engagement in an online setting. This included revised assessments, associated instructions, and rubrics to improve clarity and align with course objectives. The physical "in-person" front desk was transitioned to a virtual front desk where students could log into the desk via Zoom to ask questions. A CSPD professional staffs the desk from 9:00am-5:00pm Monday to Friday.

New CSPD professional development programming over the Summer 2020, included the following initiatives: revamped face-to-face programming to enhance student and alumni engagement during migration to virtual formats; creation of several new online workshops to address Covid-19 implications for students' internship and full-time job searches; and how to navigate the digital recruitment process, including Covid-19 Career Conversations and Back-to-Business Bootcamp. Also, the creation of a communication and event strategy targeted to support the transfer student population to ensure the specific needs of this population were met. Over the Summer of 2020, CSPD redesigned its undergraduate CSPD Canvas courses including updates to content and new architecture to improve user navigation, as well as transitioned the Canvas courses from modules to pages, allowing for greater usability utilizing a new navigational structure.

Enhanced CSPD communication initiatives included: a new weekly undergraduate email sent via Handshake software to communicate upcoming CSPD events and services with students; and transitioning of in-person events like ResumePalooza (resume critique sessions) and mock interviewing programs to virtual sessions in Zoom. For recruitment, the following changes were made: transitioning the traditional in-person Fall Connection internship/job fair to a $100 \%$ virtual internship/job fair; moving all "on-campus" interviews to virtual interviews; inviting prospective employers to participate in virtual class visits and panels; and creating a new virtual 
career-fair recruitment event for 2020 graduates to participate in employer meet ups, and conversations with employers who were actively hiring students for internships/jobs.

Analysis of open-ended student comments for the Spring 2020 survey revealed positive feedback about the initial CSPD response to the pandemic, as well as the professional development engagement initiatives, especially joining and participating in an SPO for the student's major, and CSPD helping students find internships, through networking events. Students also mentioned other networking opportunities, especially with classroom professors; as well as with academic advisors, and meeting peers outside of an SPO (e.g. through case competitions). These additional networking opportunities also helped students with their personal and professional development. Contined collection of such open-ended comments allows for more in-depth analysis of increasing student engagement involvement during the pandemic. As the Fall 2020 semester winds down, these CSPD professional development programming and communication initiatives will remain in place for the Spring 2021 semester. Although no formal survey-based evaluation data has been collected on these new initiatives, Fall 2020 qualitative feedback from students, staff, and employers has been positive.

\subsection{Study Limitations}

There are study limitations, perhaps the most obvious is the lack of additional data comparing student engagement and anticipated employment groups for those with versus without an internship further into the pandemic. The SSSS is an exit survey given as the business students' graduate. Although the same survey is also given in late Fall (to summer and winter graduates) the sample size is much smaller versus the Spring SSSS. In addition, the dramatic decrease in sample size (participation percentage) from 2019, $\mathrm{n}=749(70 \%)$ to $2020, \mathrm{n}=$ 445 (37\%), when the pandemic first began is troubling. As such, a comparable sample size to the 2019 survey needs to be collected in the next SSSS, with stronger encouragement of voluntary student participation. There are other study limitations to note. The SSSS is a retrospective survey, with students needing to accurately remember when they completed measured variables (e.g., joined an SPO; how many SPO meetings on average they attended; when they completed their professional development). It is difficult to determine how much the early pandemic onset affected these students' retrospective responses. How a student completed their professional development, i.e., taking BA 2101 versus completing required workships/seminars, was not distinguished. All students with at least one internship, regardless of number, were grouped together. The sample sizes for students having an increasing number of internships were very small and prevented more nuanced independent sample t-test analyses. The employment variables measured anticipated, and not actual, employment just prior to graduation. However, since actual employment typically occurs after the student graduates, the SSSS cannot measure this. It would be ideal to track students after they graduate to compare full-time employment for the two internship groups. Participants in this study were full-time business undergraduates at a large, state-supported urban university. Other college student samples, e.g., non-business, part-time, from other college settings, e.g., rural, private, etc., need to be analyzed using these variables to test the generalizability of findings.

\subsection{Conclusion}

As colleges and universities around the world grapple with the impact of the ongoing pandemic on their enrollments, it is important for research to not only focus on student health-related issues and academic learning, but also their professional development. The goal of this study was to demonstrate the continued importance of CPDC support for business-related internships for student PDE and anticipated employment upon graduation from pre-pandemic to early stage of the pandemic. This goal was met. It is expected that the challenges of helping college students continue to find internships, as well as supporting their SPO involvement, professional development, and anticipated employment, during the pandemic should be met through the above-mentioned recent initiatives taken by the business school CPDC (CSPD). Continued evaluation of these initiatives can be done in the next scheduled SSSS data collection. However, the encouraging initial results found suggest expanding the CPDC business school model, by establishing CSPDs for other schools within the University with a sufficient student major enrollment, e.g., Engineering; Science; Education; Liberal Arts; Public Health; and Media \& Communication. Such school-specific CPDCs can develop professional development programming initiatives more specifically focused on their students' needs versus the general University CPDC. In addition, the CPDC business school model may be readily applicable to other business schools at other Universities, where there is sufficient business student enrollment to support such resource allocation.

\section{References}

Beltekin, E., \& Kuyulu, I. (2020). The effect of Coronavirus (Covid-19) outbreak on education systems: Evaluation of distance learning system in Turkey. Journal of Education and Learning, 9(4), 1-9. 
https://doi.org/10.5539/jel.v9n4p1

Blau, G., Blessley, M., Kunkle, M., Schirmer, M., \& Regan, L. (2017). Toward understanding business student professional development engagement. Journal of Education for Business, 92(3), 145-152. https://doi.org/10.1080/08832323.2017.1302916

Blau, G., \& Lopez, A. B. (2020). Exploring correlates for paid versus unpaid internshipsor co-ops for graduating business students. Journal of Education for Business, 95(6), 393-401. https://doi.org/10.1080/08832323.2019.1668744

Blau, G., \& Snell, C. S. (2013). Understanding undergraduate professional development engagement and its impact. College Student Journal, 47, 689-702.

Blau, G., Williams, W., Jarrell, S., \& Nash, D. (2019). Exploring common correlates of business undergraduate satisfaction with their degree program versus expected employment. Journal of Education for Business, 94(1), 31-39. https://doi.org/10.1080/08832323.2018.1502144

Cohen, E., \& Davidovitch, N. (2020). The development of online learning in Israeli higher education. Journal of Education and Learning, 9(5), 15-26. https://doi.org/10.5539/jel.v9n5p15

James, C. S., Stokes, A., \& Parker, R. S. (2015). A 20-year examination of the perceptions of business school interns: A longitudinal case study. Journal of Education for Business, 90(2), 103-110. https://doi.org/10.1080/08832323.2014.988201

Knouse, S. B., \& Fontenot, G. (2008). Benefits of the business college internship: A research review. Journal of Employment Counseling, 45, 61-66. https://doi.org/10.1002/j.2161-1920.2008.tb00045.x

Liu, C. H., Pinger-Amaker, S., Ham, H. C., \& Chen, J. A. (2020). Priorities for addressing the impact of the Covid-19 pandemic on college student mental health. Journal of American College Health. Published online October 13, 2020. https://doi.org/10.1080/07448481.2020.1803882

Mansoor, J. (2020). Remote education during a nationwide pandemic: Teaching and learning (dental teachers and students) during Covid-19. Journal of Education and Learning, 9(4), 140-150. https://doi.org/10.5539/jel.v9n4p140

Marks, M. B., Haug, J. C., \& Hu, H. (2018). Investigating undergraduate business internships: Do supervisor and self-evaluations differ? Journal of Education for Business, 93(2), 33-45. https://doi.org/10.1080/08832323.2017.1414025

Munoz, L., Miller, R., \& Poole, S. M. (2016). Professional student organizations and experiential activities: What drives student intentions to participate? Journal of Education for Business, 91(1), 45-51. https://doi.org/10.1080/08832323.2015.1110553

National Association of Colleges and Employers. (2020). Nace Center. Retrieved November 16, 2020, from https://www.naceweb.org/

Reeves, J. J., Longhurst, C. A., San Miguel, S. J., Juarez, R., Behymer, J., Ramotar, K. M. ... Millen, M. (2020). Bringing student health and well-being onto a health system EHR: The benefits of integration in the Covid-19 era. Journal of American College Health. Published online November 12, 2020. https://doi.org/10.1080/07448481.2020.1843468

Sagen, H., Dallam, J., \& Laverty, J. (2000). Effects of career preparation experiences on initial employment success of college graduates. Research in Higher Education, 41(6), 753-767. https://doi.org/10.1023/A:1007072705601

SPSS-PC (version 25). (2015). Statistical package for the social sciences. Chicago: IBM Corporation.

\section{Copyrights}

Copyright for this article is retained by the author, with first publication rights granted to the journal.

This is an open-access article distributed under the terms and conditions of the Creative Commons Attribution license (http://creativecommons.org/licenses/by/4.0/). 